\title{
Essay
}

\section{A Ramble through the Cell: How Can We Clear Such a Complicated Trail?}

\author{
Joseph A. Bobich \\ Department of Chemistry, Texas Christian University, Fort Worth, TX 76129
}

Submitted December 27, 2005; Revised March 29, 2006; Accepted March 30, 2006

Monitoring Editor: Julio F. Turrens

\begin{abstract}
The arrangement of course information in a logical sequence for molecular life science (MLS) courses remains a matter of some controversy, even within a single subdiscipline such as biochemistry. This is due to the explosion of knowledge, the latest bioinformatic revelations, and the observation that new discoveries sometimes reveal specific connections between previously disparate topics. However, the general outlines of biomedical information are in place, at least the knowledge that should be conveyed to undergraduates taking cell and molecular biology and biochemistry. Despite the increasing amount and complexity of the information to be presented, integration and unification are possible because the molecular reactions and interactions that underlie all life processes are coming into view: they are common to all cellular structural rearrangements, nucleic acid functions, and biochemical reactions, whether of plant or animal origin. Also, it is no longer possible to draw clear boundaries between cell biology, biochemistry, and molecular biology that would not violate the fundamental unity of our understanding. Therefore, an arrangement of content is proposed for a two-semester course that aims to present a unified portrait of upper-division undergraduate MLS.
\end{abstract}

\section{INTRODUCTION}

Modern bioinformatics is revealing that more or less everything is connected to everything else in a cell (Zhang et al., 2005). We also are moving rapidly toward the conclusion that all cells operate by similar principles and concepts. These findings present a new challenge for teachers: conveying these innumerable connections by means of a linear but integrated sequence of lectures occurring over one or two semesters. How a cell functions at the molecular level cannot be presented all at once until the mythical "magic pill/ injection" is invented, so the most we can hope to achieve is that we convey information that reflects these interrelations, despite the linear sequence of classes that will be presented, while not overwhelming our students.

Content of biochemistry, cell biology, and molecular biology courses has received occasional attention, as well it should, given the rapid expansion and evolution of the knowledge base of the disciplines. Jakubowski and Owen (1998) have suggested a sequence based on "the logic of chemistry." Boyer (2000) rearranged his biochemistry course

DOI: $10.1187 /$ cbe. $05-12-0138$

Address correspondence to: Joseph A. Bobich (j.bobich@tcu.edu). sequence to place nucleic acid structure and function before metabolism. Of course, discussions of the curriculum always are temporally framed by what Mehler (1988) called "arbitrary selection (therefore, arbitrary exclusion) of material."

Jakubowski and Owen (1998) advanced the topic by framing it in terms of "four preeminent biological questions" and "three major recurring chemical principles" for their course design. However, knowledge is advancing so rapidly that such questions must, inevitably, change from time to time. Similarly, topic order based on "evolving chemical logic" may turn out to be formulated on shifting sands as established interactions increase and the logic evolves. As examples, who could have correctly guessed in advance that succinate dehydrogenase would be a tumor suppressor (Selak et al., 2005) or that the proteasome is involved in the regulation of gene expression (Lee et al., 2005)? Thus, we must aim at a moving target.

Boyer (2000) has suggested a rearrangement of a traditional biochemistry course sequence to place coverage of metabolism after nucleic acid structure and function. He argued that, as research beginning from nucleic acid modifications has continued to play an increasingly prominent role, so too should coverage of nucleic acids be enhanced and made more prominent. "Other molecules and biological 
processes can then be treated as the direct results of the nucleic acids" (Boyer, 2000).

In this essay, I describe an integrated, two-semester Molecular Life Science (MLS) sequence that rambles through areas of the cell and begins with vocabulary, continues with the machinery and the cell boundary, and ends with a picture of the cell at work. It attempts to create a trail of lectures that gives students a unified picture of molecular cell function by combining cell and molecular biology and biochemistry. Here nucleic acid and protein synthesis and trafficking occur before metabolism. It is difficult to understand how one can effectively teach what the molecular machinery does (produce metabolism and its regulation) before one teaches what the machinery is and how it works. Can one understand how some metabolic pathways are localized in metabolomes without first understanding how proteins adhere to each other?

This arrangement has been tested for three years, and Texas Christian University (TCU) students prefer it for situational, but simple and clear, reasons (discussed in Assessment, below). Nevertheless, beyond preferences of students at a particular school, there are logical reasons for taking this approach. They arise out of the goal and objectives of the course (below).

\section{CONTEXT FOR THE COURSE}

Requirements for the Biochemistry/MLS sequence include Organic Chemistry and at least a year of science major's Biology. At TCU, concurrent registration in Physical Chemistry is recommended. Many students already have taken Genetics and the Cell/Molecular/Developmental Biology course, which are helpful, but are not required. The Biochemistry/MLS sequence is considered to be a capstone experience for the pre-Health Professions program and is taken in the Senior year or in the Junior year before performing Senior Research. The MLS sequence is required for a B.S. in Biochemistry or Neuroscience and is strongly recommended for the B.S. in Biology. Placement and requirements for such a course sequence must be determined by each school as needs and abilities dictate.

\section{COURSE GOAL AND OBJECTIVES}

The goal of the course is to upgrade student knowledge, abilities, and attitudes through an appreciation of the chemical unity of all life. To do that, cellular, molecular, and biochemical concepts are presented in a way that provides students with a unified view of cell functions. Philosophically, students should understand that our humanity recapitulates our physiology, which recapitulates our cell and molecular biology and biochemistry, our MLS. The payoff for the students is that they will understand what is going on inside their skin at the molecular and cellular levels.

The objectives of the course are (to mimic the course goals of Derstine [2002]): “. . . that students 1) gain an understanding of the principles and concepts of cell and molecular biology [and biochemistry], 2) develop an appreciation for how these principles and concepts are important to [us, and]
3) demonstrate an ability to think critically using these principles and concepts."

This goal and these objectives raise several questions.

1. What can we realistically hope our students will retain and take with them from our courses? As Bell (2001) points out, "There is now too much information around for anyone to know and memorize. ..." So, do we cherry pick the facts to be retained? That seems unwise because a) facts are harder to retain than principles and concepts, b) many of our current "facts" will turn out to be wrong (as of last month, it seemed that the facts about how the ribosome catalyzes peptide bond formation changed every week), and c) principles and concepts are more important than facts, representing large collections to facts as they do. Therefore, our students will benefit most from being expected to retain concepts and principles, using facts as examples and illustrations of those concepts and principles. These are not novel observations.

2. Can a unified, integrated picture of the MLS be achieved and presented? Many, if not most, of the important principles and concepts of MLS have been discovered by now. Even when entirely new vistas open before us, for example, miRNA and siRNA, they are based on well-established principles such as Watson-Crick base pairing. And even if entirely new concepts arise, they may change our perspective on previous work, but they are unlikely to entirely overturn established concepts and principles. In fact, what we know now does fit into a unified picture (Huang, 2000), and that being so, don't we have a duty to present it to our students that way?

3. Are there advantages for alternative presentations, for example, segregating chunks of MLS knowledge into separate courses and departments? Some may be able to do so, but for several years I have been unable to draw bright, sharp distinctions and dividing lines between biochemistry and molecular biology and cell biology. When I try to do so, the exercise seems to cause more harm than it does good. Form, function, and chemistry are so beautifully and inextricably intertwined for us now that even when you discuss an area that is mostly in one discipline, for example, biochemical metabolic pathways, how could you leave out the molecular and cell biology regulatory events that govern metabolism? Again, Bell (2001) precedes me: "Let me dispel the idea that biochemistry and molecular biology are in any way separate disciplines: both areas ask questions about structure-function relationships at the molecular and atomic level and also at the cellular/intracellular level."

\section{HOW DOES THE LECTURE ARRANGEMENT SUPPORT THE GOALS AND OBJECTIVES?}

This course is divided into four parts (plus a few "special topics" at the end). The beginning is vocabulary, next how the machinery of life functions, then we put the membrane around it, and last, the covalent reactions that the machinery uses to keep life humming. This linearly forms a natural hierarchy that students appreciate. 


\section{Philosophy for Choice of Material}

A compromise must be achieved between completeness of coverage and the constraints of time, even in a two-semester sequence. Here the focus is on the basic unit of life, the cell, that is, the cell membrane and what is inside it, plus external influences on the cell such as the extracellular matrix, blood $\mathrm{pH}$ and nutrients, and hormonal effects. Such chemistry must be covered to properly acknowledge external influences on the cells' inner workings. Though focused on the cell, bodily functions also must intrude from time to time. How could one discuss our breakdown of biopolymers without mentioning the involvement of the stomach and gut? Similarly, students seem to like it when the benefits of aerobic exercise are mentioned during a discussion of muscle function. However, topics that are primarily concerned with interactions of different parts of the body (except for the metabolic movements of glucose, lactic acid, amino acids, hormones, etc.) are considered to be "the next level up" (physiology) and are left for other courses.

When covering the entire cell, there are quite a few principles and concepts to elucidate. Surely, we understand that students forget much of what they are taught. For an introductory MLS course, can we hope for more than that the best students inculcate a deep and meaningful understanding of those principles and concepts and how they interact? If they leave the course with that, they will have a firm foundation for specialized study. If students can also retain examples that illustrate the principles and concepts, so much the better. But retention of any significant percentage of the millions of facts that are the particular details of MLS is out of the question.

\section{TCU's Two-Semester MLS Sequence}

The first lecture at TCU provides an evolutionary overview of MLS, beginning with Dhobzansky's remark that "Nothing in biology makes sense except in the light of evolution" (see Box 1 and the link below). The second lecture is an overview of the flow of information that produces life (a review for most students and an introduction to some of the modern tools and techniques used to study that flow of information). Then, in lectures 3 through 8 , the "vocabulary" is introduced, beginning with the structures and functions of many of the molecules. Students seem to intuitively understand that it is not possible to comprehend the molecular logic of the cell without acquisition of some vocabulary, even if that means applying brute force memorization before conceptual learning. Nevertheless, it is useful to emphasize that point. Next, the cellular machinery is introduced in lectures 9 through 42. After lecture 24 many courses would enter into a discussion of intermediary metabolism. Here, the course is rearranged to present nucleic acid structure and function before metabolism (see Box 1). Then, after the finished protein products have moved to the outer limit of the cell, membrane processes are introduced just before metabolism. This progression from vocabulary to machinery to membranes to metabolism seems to be a way of presenting a complex, integrated constellation of topics in a logical sequence. Class notes for each topic and other material may be viewed at http://lib.tcu.edu/www/ ereserve/BIOCHEM_50133_50143/ereservepage.shtm.

\section{A Comparison of Course Content}

A comparison of the content of this course with some others suggests that the course sequence presented here covers more topics than they do. Topics in the MLS sequence that do not appear in Boyer's "irreducible elements" include, for example, protein processing, trafficking, secretion, and endocytosis, all as a follow-up to protein synthesis. Some of these topics are also included in our Biology Department's Cell, Molecular and Developmental Biology course, which covers the subject matter of Molecular Biology of the Cell Chapters 4-13, 15, 17, 19-21, and 23 (Alberts et al., 2002).

The two-semester biochemistry sequence provided by the Biosciences Department at Minnesota State University in Moorhead represents the classical, two-semester approach to the subject. It begins with 25 lectures that introduce the vocabulary, protein chemistry and functions, enzymology, and enzyme kinetics. That leads straight into metabolism, beginning with a review of thermodynamics. After 35 lectures on metabolism, signal transduction is discussed in five lectures, cancer in three, nutrition in two, and membranes and neurochemistry in four lectures. Near the end of the sequence, a set of activities on structural biochemistry is performed that utilizes Internet resources. It is likely that a similar approach may be taken at your university. However, some nutrition is covered in the MLS class on coenzymes and other classes, for example, discussion of essential fatty acids in lipid biosynthesis, and the mechanism of neurotransmitter release is discussed in protein trafficking. Other topics in nutrition and neurochemistry are not covered in the MLS sequence. However, classes 25-42, 44-47, and 66-70 (see Box 1) are not covered in the Moorhead Biochemistry Sequence.

Better-endowed universities can afford to have more focused courses. From the MIT Open Courseware site, it was learned that their Cellular Neurobiology course concentrates on the cell biology of neurons, including their neurochemistry and biophysics, with a concentration on the synapse. Similarly, the MIT Molecular Biology course focuses on "DNA replication and repair, genetic recombination, gene expression, RNA processing, and translation." Direct comparison of the MLS sequence with MIT Biological Chemistry I and II cannot be made because Biological Chemistry I does not appear online. Biological Chemistry II seems to be a higher level recapitulation of selected subjects that focuses on four topics: cell components, the synthesis of fatty acids and related compounds, polypeptide synthesis, and chaperones and the proteasome. Thus, none of the other courses examined contain all of the topics presented here.

The residual impression one obtains from this type of investigation is that some courses have become fragmented and individualized because a continuing tsunami of biomedical information has swept researchers into increasingly separated tide pools of teaching, while many other courses cling to the high ground of tradition. The course sequence presented here, on the other hand, was created by combining the topics covered in most molecular, cell, and chemical biology courses, weeding out duplications and overlaps, and then arranging the subjects into a (hopefully) useful sequence. 
Box 1. Course content

\section{FIRST SEMESTER}

\section{Vocabulary}

1. Origins of life

2. Genomes and flow of genetic information

3. Bonds, $\mathrm{H}_{2} \mathrm{O}$, and buffers

4. Amino acids and peptides

5. Monosaccharides and disaccharides

6. Oligosaccharides, polysaccharides, and glycoproteins

7. Simple lipids, complex lipids, and micelles

8. Nucleotides, structures of DNA, and RNA

\section{Machinery}

9. Protein structure

10. Protein purification and characterization

11. Protein sequencing, structure-function relationships, and chemical peptide synthesis

12. Bioenergetic principles

13. Protein folding (and unfolding) in vitro

14. Enzyme mechanisms

15-18. Enzyme kinetics I-IV

19. Catalytic strategies and catalytic RNA

20. Coenzymes

21. Binding phenomena and catalytic antibodies

22. Noncovalent enzyme regulation

23. Oxygen-transporting and -storing proteins and plasma $\mathrm{pH}$

24. Covalent enzyme regulation

25. Sequencing and chemical synthesis of DNA

26. Chromatin structure and nuclear organization

27. DNA replication

28. Recombination in vivo

29. DNA mutations and repair

30. Genetic engineering and biotechnology I

31. Genetic engineering and biotechnology II

32. Regulation of gene expression before RNA synthesis I

33. Regulation of gene expression before RNA synthesis II

34. RNA transcription, regulation of gene expression during and after RNA synthesis, and premRNA end modifications

35. RNA splicing, alternative splicing, and RNA interference

36. rRNA and tRNA processing, RNA export, selective utilization, and turnover

37. Structures of tRNA, synthetases and ribosomes, and genetic code

38. Initiation of protein synthesis

\section{SECOND SEMESTER}

\section{Machinery (continued)}

39. Polypeptide elongation and termination and protein quality control

40. Protein folding in vivo

41. Protein processing

42. Protein trafficking

\section{Membrane Processes}

43. Lipoproteins and membranes

44. Extracellular matrix

45. Endocytosis and protein turnover

46. Active transport

47. Membrane channels

48-50. Hormones and signal transduction I-III

\section{Flow of Ions and Molecules}

51. Introduction to intermediary metabolism and glycolysis

52. Lipid metabolism

53. Amino acid metabolism and urea cycle

54. Citric acid cycle

55. Electron transport and oxidative phosphorylation

56. Mitochondrial shuttles and cataplerotic and anaplerotic reactions

57. Photosynthesis and photosynthetic phosphorylation

58. Photosynthetic carbon fixation

59. Gluconeogenesis

60. Polysaccharide synthesis and hexose interconversions

61. Lipid biosynthesis

62. Phospholipid, sphingolipid, and steroid biosynthesis

63. Regulation of cholesterol homeostasis

64. Nitrogen and sulfur metabolism

65. Amino acid biosynthesis

66. Integration of metabolism

\section{Special Topics}

67. Cytoskeleton

68. Muscle function

69. Development

70. Cell division cycle and cell death

71. Viruses, retroviruses, and other retroelements

72. Cancer

73. Individual student presentations on research topics of their own interest

\section{ASSESSMENT}

Near the end of April 2001, students in the class were asked, "As mentioned previously, unlike your course, most biochemistry years place metabolism before DNA, RNA, and 
protein synthesis, trafficking, and protein turnover. Compare and contrast these two forms, indicating how they have/would have worked out for you." More than $80 \%$ (7 of 8) of the students preferred the course the way it was presented. In 2002, essentially the same question was asked: "In some biochemistry courses, the 'molecular biology' parts come after metabolism, for example, carbohydrate breakdown and synthesis, lipid breakdown and synthesis, etc., but here they come before. Which would/do you prefer and why?" In year 2, 82\% (9 of 11) of the students preferred this lecture order. Very similar impressions were obtained in 2003, when the question was "Some biochemistry courses have metabolism after enzymes and coenzymes, and before DNA, RNA, and protein synthesis. Do you think that would have worked better for you or not? Why/not?" $83 \%$ (5 of 6 ) of the students preferred the courses as presented. In summary, over 3 years $84 \%$ (21 of 25 ) of the students who took the whole sequence preferred this arrangement.

It is probably true that some part of this positive response is due to the students liking the lecture order they were exposed to rather than a different lecture order. To minimize such effects, the students were given at least 1 week to respond, they were asked to more or less fill a page with their comments, and their responses were anonymous. It also was emphasized that the only purpose of the exercise was to improve teaching for future students, so full and frank appraisals were essential.

Over 3 years, the students preferred this lecture arrangement by at least three to one, primarily because 1) they usually have had earlier exposure to some cell and molecular biology (in our Introductory Biology and two lower level Genetics and Cell/Molecular/Developmental Biology courses), 2) they saw reiteration of molecular and cell biology as a desirable prerequisite for effective learning of biochemistry, and 3) deferring metabolism until the second semester moves it closer to the time when it will be repeated, for many of our undergraduates, in medical school.

\section{DISCUSSION}

It should be admitted at the outset that, because of the fact that most college classes are works of individual craftsmanship, the course content of this sequence differs in some ways from Boyer's Tables 2 and 3 (Boyer, 2000) and other courses. There are two principal reasons for such differences: teacher preferences and class composition. Teacher preferences appear both in relation to topic arrangement and course content. For example, at TCU the Bioenergetic Principles lecture (essentially a brief review of biophysical chemistry) is presented early on, between protein conformation and protein folding, rather than near the end of the course, just before metabolism (Boyer, 2000). I feel that biophysical principles need to be reviewed before introduction of the powerful concept of the "inverted bumpy cone" model for protein folding energetics. Even though there is a large subsequent gap in our course between Bioenergetic Principles and metabolism, it does not take long to remind the students of the concept that, if a metabolic reaction goes to near completion, it is because a combination of the standard Gibbs free energy change and the actual concentrations of the reactants and products produces an overall large negative free energy change.
Differences also may occur because of the nature and interests of the students who take the course. Most of the students who take the MLS/Biochemistry sequence at TCU go on to medical or dental (or, occasionally, veterinary) schools. It is generally acknowledged among the community of molecular life scientists that a doctor who has received undergraduate MLS training is likely to be better trained than those who have not. To me, that means conveying a fundamental understanding of how the cell functions at the molecular level. Thus, students are provided with information on a wide variety of biomedically useful library resources and Web sites, but they are not required to investigate and utilize any as part of their classroom work until the very end of the sequence when students deliver individual oral presentations to the class on modern research topics.

Comments and tips on student presentations are available through the link, and two references to aid information seeking (Brown, 2000; Calvo, 2000) are distributed at the start of the second semester.

\section{Dealing with MLS Knowledge Plasticity}

Does the list of topics in the Box 1 completely cover the cell? No, and it will even less in the future. The list serves only as this quarter's point of departure. Because of the rapidly expanding knowledge base, the nature of the topics and their order in MLS courses is inherently malleable. Box 1 is a list of topics covered lately. Perhaps it is time to consider adding material on the biochemistry of obesity (the most common problem future doctors will have to deal with, apparently) and the biochemistry of circadian rhythms, perhaps by reducing the number of enzyme kinetics classes.

\section{A Final Question}

The cell has long been considered to be the fundamental unit of life (Hooke, 1665; Leeuwenhoek, 1720). In this new millennium, we have come to understand that all cells operate by similar chemical principles and concepts. That is, we understand the chemical logic of the cell. Might now be the time to revise our courses and curricula to convey that understanding to our students in a unified way?

\section{ACKNOWLEDGMENTS}

I thank the students of Biology 50133 and 50143 and Chemistry 50133 and 50143 for their tolerance and willingness to help improve the courses for future classes. Similarly, the inspiration, help, and encouragement of Dr. Rodney Boyer is gratefully acknowledged, as is the data provided by Dr. Joseph Provost, Professor of Biosciences at the Minnesota State University, and the word processing skills of Mrs. Carolyn Banwart.

\section{REFERENCES}

Alberts, B., Johnson, A., Lewis, J., Raff, M., Roberts, K., and Walter, P. (2002). Molecular Biology of the Cell, 4th Ed., New York: Garland Science.

Bell, E. (2001). The future of education in the molecular life sciences. Nat. Rev. Mol. Cell Biol. 2, 221-225.

Boyer, R. (2000). The new biochemistry; blending the traditional with the other. Biochem. Mol. Biol. Educ. 28, 292-296. 
Brown, S. (2000). Information retrieval in biochemistry: some exercises to develop a fundamental skill. Biochem. Mol. Biol. Educ. 28, 194-199.

Calvo, S. C. (2000). Jump-starting your library research online. BioTechniques 29, 258-260.

Derstine, P. (2002). Implementing goals for noncognitive outcomes in a basic science course. Acad. Med. 77, 931-932.

Hooke, R. (1665). Micrographia: or, Some Physiological Descriptions of Minute Bodies Made by Magnifying Glasses, London: J. Martyn and J. Allestry.

Huang, P. C. (2000). The integrative nature of biochemistry: challenges of biochemical education in the USA. Biochem. Mol. Biol. Educ. 28, 64-70.

Jakubowski, H. V., and Owen. W. G. (1998). The teaching of biochemistry: an innovative course sequence based on the logic of chemistry. J. Chem. Ed. 75, 734-736.
Lee, D., Ezhkova, E., Li, B., Pattenden, S. G., Tansey, W. P., and Workman, J. L. (2005). The proteasome regulatory particle alters the SAGA coactivator to enhance its interactions with transcriptional activators. Cell 123, 423-436.

Leeuwenhoek, A. (1720). Observations upon the bones and the periosteum, in a letter to the Royal Society, from Mr. Leeuwenhoek, FRS Philosophical Trans. 31, 91-97.

Mehler, A. H. (1988). The process of graduate education. Biochem. Ed. 16, 67-70.

Selak, M. A., Armour, S. M., Mackenzie, E. D., Boulahbel, H., Watson, D. G. Mansfield, K. D., Pan, Y. Simon, M. C., Thompson, C. B., and Gottlieb, E. (2005). Succinate links TCA cycle dysfunction to oncogenesis by inhibiting HIF-alpha prolyl hydroxylase. Cancer Cell 7, 77-85.

Zhang, L. V., King, O. D., Wong, S. L., Goldberg, D. S., Tong, A. H., Lesage, G., Andrews, B., Bussey, H., Boone, C., and Roth, F. P. (2005). Motifs, themes and thematic maps of an integrated Saccharomyces cerevisiae interaction network. J. Biol. 4, 6 . 